\title{
Climate change impacts and adaptation options in the Mediterranean basin
}

\author{
Maria Loizidou' $^{1}$ Christos Giannakopoulos ${ }^{2} \cdot$ Marco Bindi $^{3} \cdot$ Konstantinos Moustakas $^{1}$
}

Received: 15 June 2016/Accepted: 3 August 2016/Published online: 18 August 2016

(C) Springer-Verlag Berlin Heidelberg 2016

The Intergovernmental Panel on Climate Change (IPCC) has identified the Mediterranean region as a climate change hot spot. In the eastern Mediterranean especially, most countries are already experiencing a rise in temperatures and increases in freshwater scarcity, forest fires, and frequency of droughts and growing rates of desertification.

Recognizing the need for timely addressing climate change impacts in Cyprus and strengthening the country's adaptive capacity, the CYPADAPT project (http://uest. ntua.gr/cypadapt) on the development of a National Adaptation Strategy was initiated in September 2011 and was successfully completed in March 2014. The Department of Environment of the Ministry of Agriculture, Natural Resources and Environment of Cyprus was the coordinating beneficiary of the project, while the Unit of Environmental Science \& Technology (www.uest.gr) of the National Technical University of Athens and the National Observatory of Athens (www.meteo.noa.gr) were the two associated beneficiaries. CYPADAPT included six stages, namely the following: a current vulnerability

Maria Loizidou

mloiz@chemeng.ntua.gr

$\bowtie$ Konstantinos Moustakas

konmoust@central.ntua.gr

1 Unit of Environmental Science and Technology, School of Chemical Engineering, National Technical University of Athens, 9, Heroon Polytechniou Street, Zographou Campus, 15773 Athens, Greece

2 Institute for Environmental Research and Sustainable Development, National Observatory of Athens, V. Pavlou and Metaxa Str., P. Pendeli, 15236 Athens, Greece

3 Department of Agri-food Production and Environmental Sciences, University of Florence, Piazzale delle Cascine 18 , 50144 Florence, Italy assessment; future vulnerability assessment; identification of adaptation measures; evaluation of adaptation measures; development of an adaptation strategy (known as the National Adaptation Plan-NAP); and monitoring and evaluation. Each stage was accompanied by active stakeholder engagement and public awareness raising. CYPADAPT utilized a range of models within a multidisciplinary expert team and assessed impacts and adaptation strategies on water, energy, infrastructure, coasts, tourism, forestry, agriculture, ecosystems services, and health. Indicatively, a demonstration video that was developed within the framework of the CYPADAPT project in order to present the multi-criteria analysis tool for giving priority to the suitable measures for adaption to climate change impacts is available to public at: https:// www.youtube.com/watch?v=AbZ_RUJi_uE. This video summarizes background information about the CYPADAPT project and its objectives, guidance in order to install and start up the developed software as well as stepby-step instructions to operate the CYPADAPT software. The project was co-financed by the LIFE + Programme (LIFE10 ENV/CY/000723), the EU financial instrument for the environment.

In order to disseminate the achievements of CYPADAPT project and to extend the efforts in the field of adaptation in the wider Mediterranean region, the working team of the CYPADAPT project proceeded with the organization of the ADAPTtoCLIMATE Conference on the 27th and 28th of March 2014 at the Filoxenia Conference Centre in Nicosia, Cyprus. The main aspiration of the ADAPTtoCLIMATE Conference was to bring together scientists, practitioners, and decision makers across a wide range of disciplines and sectors to share insights into the climate change challenges and opportunities and to present adaptation tools and strategies. Last but not least, the 
ADAPTtoCLIMATE Conference was intended to further support European Commission efforts in adaptation by providing nexus for up-to-date information-sharing and coordination between countries.

The papers included in this special selection address future climate change in the Mediterranean region and its impacts on a wide variety of fields including agriculture, energy demand, population health, tourism, forest fires, hydrologic regime, sea-level rise, marine environment, and fisheries with emphasis on adaptation options.

More specifically, the special issue includes 10 papers. Starting with Zittis et al. (2016), the first paper described the projected changes in heat wave characteristics in the eastern Mediterranean and the Middle East and estimated that all indices that characterize heat wave severity will strongly increase compared with the past control period. More specifically, the southern part of the eastern Mediterranean and the Middle East may be exposed to 2-3 months more combined tropical nights and hot days, while the northern part could experience increased heat wave amplitudes by $6-10{ }^{\circ} \mathrm{C}$.

Moriondo et al. (2016) discuss the impacts of heat stress on crop yields in the Mediterranean basin, and the results presented prove the importance of the appropriate characterization of crop yield distribution, the economic implications of heat stresses in a risk management context, and a possible strategy to face climate change and variability.

The paper by Giannakopoulos et al. (2016) deals with climate change impacts, vulnerability, and adaptive capacity of the energy sector. Spatial vulnerability of Cyprus was assessed via the use of the degree-day indicator in order to estimate the demands for heating and cooling in the near future using daily temperature projections given by regional climate models. The results of the impact model revealed that for the so-called cold period from November until April, a decreasing trend in electrical energy consumption is noted because of warmer conditions in the near future, while for the case of 'warm period' starting from May till October, an increasing trend in electricity consumption can be foreseen as conditions of higher temperatures are becoming more intense by 2050 . The ability of the energy sector to adapt and follow these changes was found satisfactory leading to the reduction in the overall vulnerability of the energy sector to future climate change.

Tsangari et al. (2016) discuss human mortality and the role of temperature and particulate air pollution through the use of a generalized linear model with quasi-Poisson regression. The research results showed that high temperatures had important effect on mortality with higher mortality rates, independent of seasonality and humidity. Differences were noted between costal and urban areas. In general, it was found that mortality risk increased sharply when exceeding a temperature threshold. A direct heat effect was evident. The risk was found higher on the current and next day of a severe heat event. PM10 was not found to have a confounding effect on the relationship between mortality and temperature.

Lemesios et al. (2016) refer to future heat-related impact assessment of tourism industry to climate change. The research was made with the use of "Tourism Climate Index," as well as "Beach Climate Index." The results using the first index for the distant future period showed exclusively acceptable conditions regarding general tourism activities during summer in contrast to the good/very good conditions in the present climate. Conversely, this type of tourism seems to be benefited during autumn and spring. Tourism Climate Index and consequently touristic activities get better in the distant future comparing with the present climate. On the other hand, concerning beach tourism, future projections showed that it will not be affected in a negative way by future climate change and any changes will have positive effect.

Three papers deal with climate change-related issues in Greece. In particular, at first, Mitsopoulos et al. (2016) describe fire behavior under changing climate in a Mediterranean landscape that can support the organization of fire suppression strategy and management. More specifically, climate change impacts were assessed for a number of parameters including the rates of fire growth, spread, and fire line intensity for a typical Mediterranean landscape. The conclusions of this paper can be of great value in order to enhance protection from fire quantifying the outcome of the expected future climate periods on fire suppression difficulty in Mediterranean areas.

Then, Doulgeris et al. (2016) focus on the impacts of climate change on the hydrology of two Greek Natura 2000 sites, namely Cheimaditida and Kerkini Lakes. The water balance of both lakes was simulated via the use of historical climate data and different emission scenarios for the period 2020-2050 and for the period 2070-2100. Based on these scenarios, future climate scenarios were described. Climate change is expected to influence the hydroperiod of the two wetlands. In order to protect the wetland's biodiversity, it is necessary to ensure sustainable management of water resources.

Next, Monioudi et al. (2016) assess the vulnerability of 71 beaches in eastern Mediterranean that are either already developed or have a reasonable development potential and assess their erosion risk under sea-level rise to sea-level rise with the aim to record the spatial characteristics and other attributes, such as topography, sediments, and accessibility. Beach retreats were predicted by ensembles of six cross-shore (1D) analytical and numerical morphodynamic models, set up/forced on the basis of collected/collated information and three sea-level rise 
scenarios $(0.26,0.82$, and $1.86 \mathrm{~m})$; these retreats were then compared with the recorded maximum beach widths.

Furthermore, Jimenez et al. (2016) deal with the mortality of the scleractinian coral Cladocora caespitosa during a warming event in 2012 and conclude that such events can affect corals and marine organisms significantly, to the extent where a very small portion of polyps/colonies present resilience during thermal stress, while temperature anomalies are associated with the mortality event.

Finally, the irrigation canals in Southern France and their contribution to dealing with adaptation is the subject of the work by Aspe et al. (2016). This last paper draws emphasis on the multiple ecosystem services that are offered by the irrigation canals apart from water provision for agricultural production.

We would like to thank the Editor-in-Chief of Regional Environmental Change, Prof. Dr. Wolfgang Cramer, for his valuable comments and suggestions during the whole process of this special issue. Finally, the LIFE + Programme of the European Commission is greatly acknowledged for providing financial support to the CYPADAPT project.

\section{Guest Editors \\ Maria Loizidou \\ Christos Giannakopoulos \\ Marco Bindi \\ Konstantinos Moustakas}

\section{References}

Aspe C, Gilles A, Jacque M (2016) Irrigation canals as tools for climate change adaptation and fish biodiversity management in Southern France. doi:10.1007/s10113-014-0695-8
Doulgeris C, Papadimos D, Kapsomenakis J (2016) Impacts of climate change on the hydrology of two Natura 2000 sites in Northern Greece. doi:10.1007/s10113-015-0857-3

Giannakopoulos C, Psiloglou V, Lemesios G, Xevgenos D, Papadaskalopoulou C, Karali A, Varotsos K, Zachariou-Dodou M, Moustakas K, Ioannou K, Petrakis M, Loizidou M (2016) Climate change impacts, vulnerability and adaptive capacity of the electrical energy sector in Cyprus. doi:10.1007/s10113-0150885-z

Jimenez C, Hadjioanou L, Petrou A, Nikolaidis A, Evriviadou M, Lange MA (2016) Mortality of the scleractinian coral Cladocora caespitosa during a warming event in the Levantine Sea (Cyprus). doi:10.1007/s10113-014-0729-2

Lemesios G, Giannakopoulos C, Papadaskalopoulou C, Karali A, Varotsos K, Moustakas K, Malamis D, Zachariou-Dodou M, Petrakis M, Loizidou M (2016) Future heat-related impact assessment of tourism industry to climate change in Cyprus. doi:10.1007/s10113-016-0997-0

Mitsopoulos I, Mallinis G, Karali A, Giannakopoulos C, Arianoutsou M (2016) Mapping fire behaviour under changing climate in a Mediterranean landscape in Greece. doi:10.1007/s10113-0150884-0

Monioudi IN, Karditsa A, Chatzipavlis A, Alexandrakis G, Andreadis OP, Velegrakis AF, Poulos SE, Ghionis G, Petrakis S, Sifnioti D, Hasiotis T, Lipakis M, Kampanis N, Karambas T, Marinos E (2016) Assessment of Vulnerability of the Eastern Cretan Beaches (Greece) to sea level rise. doi:10.1007/s10113-0140730-9

Moriondo M, Argenti G, Ferrise R, Dibari C, Trombi G, Bindi M (2016) Heat stress and crop yields in the Mediterranean basin: impact on expected insurance payouts. doi:10.1007/s10113-0150837-7

Tsangari H, Paschalidou A, Vardoulakis S, Heaviside C, Konsoula Z, Christou S, Georgiou KE, Ioannou K, Mesimeris T, Kleanthous S, Pashiardis S, Pavlou P, Kassomenos P, Yamasaki EN (2016) Human mortality in Cyprus: the role of temperature and particulate air pollution. doi:10.1007/s10113-015-0793-2

Zittis G, Hadjinicolaou P, Fnais M, Lelieveld J (2016) Projected changes in heat wave characteristics in the eastern Mediterranean and the Middle East. Reg Environ Change. doi:10.1007/ s10113-014-0753-2 